\title{
Place and Contested Identity: Portraying the Role of the Place in Shaping Common Sociopolitical Identity in the Chittagong Hill Tracts, Bangladesh
}

\author{
H.M. Ashraf Ali
}

This research is about how a collective socio-political identity, the 'Pahari' (the hill people), is constructed by the ethnoculturally diversified groups of indigenous people in the Chittagong Hill Tracts (CHT) of Bangladesh. While conducting my PhD dissertation fieldwork in the CHT, I experienced that most of the non-Bengali ethnicities use a common term 'Pahari' in their everyday conversations. This term derives from the Bengali word 'pahar', which means "bill"; and the term 'Pahari' is the term used by 'the inhabitants of hills' or 'the hill people' to introduce them to visitors, tourists, or in their everyday conversations. Of course, they have their own distinctive and individual ethnic identity marked by language, religion, kinship, and marriage system (e.g., Chakma, Marma, Tanchangya). Thus, they have two different identities: the ethnic identity and the common socio-political identity. The influence of hills, land, forest, Kaptai Lake, and above all, the ecological system of this region on the economy and the lives of the people who live here is immense. In this research paper, I will reflect on how a particular place, a different geographical setting, is used to bring group members of diverse ethnicities together in order to construct a common socio-political identity. Although the 'place' is central to the construction of this Pahari identity, social, economic, and political relations with the Bengalis appear as determining factors in adopting such collective identity by the culturally differentiating ethnicities in the CHT. Finally, I will describe how and why the Pahari identity is contested and contradictory in broader socio-political context in Bangladesh.

$\mathrm{T}$

he historical development, strategic geograhical position, ethnocultural diversity, and economic-political significance of the Chittagong Hill Tracts (CHT) has marked it as a unique place within South Asia. The CHT is situated in the southeast corner of Bangladesh and is bordered by the Indian state of Tripura in the north and Mizoram in the east. The country of Myanmar borders in the southeastern part. In Bangladesh, this mountainous region of the CHT is comprised of three districts-Rangamati, Bandarban, and Khagrachari. The CHT has been the home of the following 12 ethnic groups for hundreds of years: Chakma, Tanchangya, Marma, Tripura, Reang, Mro, Lushai, Khumi, Chak, Khyang, Bawm, and Pankhua. These ethnic groups of people are distinct from the majority Bengali population of Bangladesh with respect to race/ethnicity, language, culture, religion and other social systems. For example, most of these ethnic groups speak in a mixed language of Bengali,
Pali, Burmese, and Assamese dialect whereas all the Bengalis of the plain speak in one language_Bengali. From religious point of view, a majority of these ethnic groups such as the Chakma, the Marma, and the Tanchangya are Buddhists and the rest of them are either followers of Hinduism or Christianity. Conversely, the majority of the Bengalis are followers of the religion of Islam.

The twelve ethnic groups largely depend on shifting cultivation, forest, and hills for their livelihoods whereas the Bengalis of the plain depend on a homogenous form of agriculture: plough-cultivation (Ahsan and Chakma 1989; Ali and Shafie 2005; Chakma 2010; Schendel 1992). Thus, the CHT is a very important region in Bangladesh for strategic geographic position and security reasons (e.g., the border with India and Myanmar), the location of hydroelectric power resources (e.g., Kaptai Hydroelectric Project), natural resources (e.g., forests and Kaptai Lake), and possible economic and tourism 
development. Sociocultural differences and cultural diversity are prevalent throughout this region, primarily due to the diversity of indigenous peoples.

However, there are different discourses, confusions, and debates about the actual identity of these ethnic groups in CHT. The people of the CHT have so far been represented as the Tribal or the Upzati in government documents from the British colonial government to independent Bangladesh. The Jummas, the Adivashi, and the indigenous people are also the parallel collective identity for the twelve ethnic groups in the CHT, which are mainly represented by the indigenous political groups, academic and independent researchers, and international human rights organizations (Ahamed 2006, 376; Ali and Shafie 2005, 68; UNDP 2009, 1). As this study observed, most of the indigenous people in the study locality use the term Pabari in their day to day conversations or to introduce themselves to others (i.e., visitors or tourists).

Sometimes they also use the term Adivashi, meaning 'the original people/inhabitants', and sometimes they use the term Jum$m a$, a term deriving from the practice of jbum chash (shifting cultivation). The term Jumma was romanticized and popularized by the indigenous political leadership to mobilize the diverse ethnic groups from the $\mathrm{CHT}$ for the resistance movement against the Bangladesh army and the immigrant Bengalis in the mid1970s. Though various international human rights organizations including the International Labor Organization (ILO) and the United Nations Development Programme (UNDP) identify these 12 ethnic groups collectively as "indigenous people" based on cultural traditions and way of life, the government of Bangladesh has recently enlisted them as "small ethnic groups" in the Bangladesh Constitution (for a more detailed discussion of this, see The Daily Star 2011).

In response, the people in the CHT differ with this government decision. Rather, they claim that they are the original inhab- itants. They emphasize four key criteria, namely the 'place' and 'time', the 'nature and sources of their livelihoods'; and the 'tradition and pattern of lifestyle' that markedly differs from the Bengalis of the plain. These Pahari people argue that they are the original inhabitants of the CHT, as they have been living in the hills for generations, at least since before the arrival of any Bengali here

In this paper, I examine how and why the CHT people from ethnoculturally diverse groups use the term Pahari. Some anthropologists have recently used the term Pahari in their research in the CHT (e.g., Ahamed 2006; Ali and Shafie 2005; Uddin 2008), but none of them contextualizes and elaborates upon it in relation to place, recent sociocultural change, and unequal power relations within the Pahari community. Considering the scope and objective of this paper, I will not elaborate about the other parallel terms such as the Jummas, Adivashi, and stereotyped identity such as Upzati or Tribal. Throughout this paper I will use both terms Pahari and indigenous to indicate all non-Bengali ethnic groups in the CHT. Sometimes, I also use the phrase 'CHT people' to denote all the nonBengali people in the CHT. However, I have observed that two common words, namely Pahari and Adivashi, are mostly used by research participants and other local people in this study area. Although Pahari and Adivashi are used as the collective socio-political identity and they have intimate relationship to a 'place' and 'time', I would rather confine my focus on the Pahari and its background and significance in relation to their economic and sociopolitical life and how it is used to differentiate the Pahari from the Bengalis of the plains.

This paper is divided into three major sections. The first section describes methodology, study locality and the ethnocultural features of the research participants and the historical/political context of the CHT. It highlights how the indigenous people attempt to bring aspects of social, economic 
and political relations with the Bengalis and the Bangladesh state together to form this sociopolitical identity. The second section explains the term Pahari and how it is used by the study community in their everyday life. It also concentrates on how the indigenous people link a place to the construction of the collective Pahari identity. Finally, it demonstrates how and why the Pahari identity is contested and contradictory in broader sociopolitical context in Bangladesh.

\section{Methodology}

My $\mathrm{PhD}$ dissertation fieldwork on microcredit, power, and poverty at Rangamati in CHT was conducted in two phases between May 2009 and July 2011. I used standard anthropological data collection techniques, including participant observation, unstructured interviews with key informants, and semi-structured focus group interviews following purposive and snowball sampling. I talked to key informants, particularly to elders and community leaders. I also used relevant secondary data such as published research works, books, and articles on the CHT people. A digital voice recorder was used to record interviews and informed consent was taken with each informant. I used ATLAS. ti 6.2, a qualitative data analysis tool, to code and thematically analyze the data (Bernard 2010; Fetterman 2010; Hammersley and Atkinson 2007).

\section{Who lives in the study locality?}

This study was conducted at Rangamati in CHT of Bangladesh. One of the significant aspects of the research area is the ethno- and sociocultural diversity present. Both indigenous and Bengali peoples reside in the CHT and practice many forms of religion. The indigenous people, collectively known as Pahari, include the Chakma, Marma, Tanchangya, Tripura, Lushai, Ahamiya, and Gurkha. Bengalis are for the most part Muslim, with a Hindu minority. The Chakma are the largest of the indigenous groups of people. The Chakma, Marma, and Tanchangya peo- ples are Buddhist. Although the Tripura followed Hinduism, most of them in this study locality are converts to the religion of Christianity. The Lushais are Christians (Chakma 2010). Assamese (locally called Ahamiya) and Nepalese or Gurkha are Hindu. Both the ancestors of the contemporary Ahamiya and Gurkha people living in the study locality migrated from Assam in India and Nepal, respectively, during British colonial rule in the 19th century. The social and cultural differences between the indigenous and Bengali population are marked by different ethnic origins, social organizations, and cultural systems (e.g., marriage, social customs, kinship, religion, and language). The Chakma, Marma, Tripura, Tanchangya, and Lushai people lived in Rangamati long before the Bengali people migrated to this region. It can be assumed from different historical sources and narratives of the local indigenous people that they are the original inhabitants of the CHT and are of Sino-Tibetan descent, belonging to the Mongoloid group (Chakma 2010, 283). Linguistically, the Chakma, Marma, Tripura, and Tanchangyas are associated with Sino-Tibetan. It appears that both the major group of people might have migrated from the Chin Hills and Arakan in Myanmar (e.g., the Chakma, Marma, Tanchangya and Lushai) and Tripura in India (UNDP 2009; Uddin 2008). Therefore, most of the indigenous people in this region are of Sino-Tibetan descent and have distinct Mongoloid racial characteristics that mark a significant ethnic and cultural difference from the Bengalis, an Indo-Aryan language group.

\section{Constructing COMMON \\ SOCIOPOLITICAL IDENTITY: \\ Political-Historical Background}

The history of economic exploitation, suffering, and antagonistic relationships between the Bengali and indigenous people in the CHT is linked to the discriminatory economic and political policies of both the Pakistani government (1947-1971) and the government of independent Bangladesh 
that formed in the early 1970s (Nasrin and Togawa 2002; Uddin 2008). In 1947, the British withdrawal from the Indian subcontinent led to the rise of two nation-states: India and Pakistan. This division of British India was based on the "two nation theory" that independence activists devised to recognize the two major religious identities in the Indian subcontinent: Hinduism in India and Islam in Pakistan (Schendel 1992, 116; Uddin 2008, 42). Today's Bangladesh and the CHT were included in the state of Pakistan because the majority of the populace was Muslim. However, the majority of indigenous populations in the CHT were non-Muslims. The Pakistani government abolished the semi-autonomous status, known as the CHT Regulation Act 1900 , of the CHT indigenous peoples in 1963. At the same time, this government imposed development projects, including the Kaptai Hydroelectric Project, which brought devastating social, economic, ecological, and humanitarian consequences (Uddin 2008, 43). The influx of Bengali people into the CHT region from the plains followed. The establishment of the Karnaphuli paper mill and rayon, timber, and plywood industries in the 1950s, financed by the World Bank, brought immense suffering for the local indigenous peoples as they lost their lands and sources of livelihoods as forests were destroyed (Nasreen and Togawa 2002, 103). The construction of the Kaptai Hydroelectric Project (1959-1962), locally known as Kaptai Dam, appeared as a curse for the people who were living here. The construction of the Kaptai Dam was financed by the United States Agency for International Development (USAID) and the World Bank (Nasreen and Togawa 2002). It is the largest dam in South Asia and created a vast reservoir of some $885 \mathrm{~km}$ (550 square miles). It was constructed without any impact assessment or any consultation with representatives of the local indigenous community. It submerged at least $40 \%$ of the total arable land of the CHT and displaced more than 100,000 in- digenous people, particularly Chakma, who were mainly sedentary rice farmers (Bhikkhu 2007, 2; Nasreen and Togawa 2002). The suffering caused by this displacement and loss of land continues to affect people today because they have not yet been able to restore this crucial economic base.

Consequently, the indigenous people began to mobilize the diverse ethnic groups in order to form a collective sociopolitical platform to protect their economy, land, and cultural identity. The first collective use of the term 'Pahari' appeared in the formation of the "Pahari Chhatro Samity" (Hill Students' Association) to protest against the discriminatory economic and political policies of the government of Pakistan in the 1960s (e.g., the Kaptai hydroelectric project and abolition of the semi-autonomous status of the CHT) (Schendel 1992, 120). The suffering, exploitation, and discrimination of the CHT people continued after the independence of Bangladesh from Pakistan in 1971. Politically motivated migration into the CHT by Bengali people occurred on a massive scale beginning in the late 1970s, backed by the military might of the state. However, a delegation of indigenous political leaders led by the Member of Parliament Manobendra Narayan Larma Chakma called on Prime Minister Sheikh Mujibur Rahman and submitted a four-point memorandum on February 15, 1972. The major aspects highlighted in this memorandum were: 1) recognition of the diverse ethnic groups of the CHT as 'indigenous people' in the Constitution of Bangladesh and the endorsement of the $\mathrm{CHT}$ as an autonomous region and setting up its own legislative assembly; 2) retention of the CHT Regulation Act 1900 in the Constitution; 3) retention of the offices of tribal chiefs such as the Chakma Circle Chief; and 4) imposition of constitutional restriction on the influx of the Bengalis in the CHT from the plains. Instead, this proposal was refused categorically by the Bangladeshi head of state. The Prime Minister instigated the indigenous 
people's delegation team to become Bengali by renouncing 'the idea of separate identity' (Mohsin 2004, 46; Uddin 2008, 45; UNDP 2009 , 4). In addition to the refusal of this proposal, the Government of Bangladesh amended rule 34 (1) of the CHT Manual in 1979 allowing the resettlement of Bengali landless people (Nasreen and Togawa 2002, 105). Through this amendment, the Government of Bangladesh legalized the settlement of outsiders in the CHT that had previously been restricted by the British colonial administration in the 1900 s (i.e., CHT Regulation 1900). It was estimated that more than 400,000 Bengalis had been uplifted from the plain districts to transmigrate to the CHT by the successive governments of Bangladesh from 1979 to the mid-1980s (UNDP 2009, 5).

Consequences of these political decisions of the Government of Bangladesh were widespread and devastating. An indigenous political party, the Parbattya Chattagram Jana Samhati Samity (PCJSS), which formed in 1972, was involved in a resistance movement against the Bangladeshi army and immigrant armed groups. This indigenous armed group was locally known as 'Shanti Bahini' (Peace Troops). The PCJSS created the notion of 'Jumma', a collective identity of all the indigenous people in the CHT, to mobilize its people to participate in this resistance movement. Consequently, an approximately two-decade indigenous resistance movement continued from 1975 to the late 1990s which cost thousands of lives and brought enormous suffering (Arens and Chakma 2002; Levene 1999; Mohsin 2004). At long last, the CHT Peace Accord between the Government of Bangladesh and the PCJSS was signed on December 2, 1997. There is still resentment among the indigenous people as the peace accord is yet to be completely implemented by the Government of Bangladesh (Chowdhury and Rafi 2001).

The influx of the Bengali people from the plains to lands that were previously oc- cupied by the different indigenous communities was a main cause of antagonism between the Bengali settlers and the indigenous communities. The relationship between the indigenous and Bengali people had broken down because the indigenous people had to leave their ancestral lands as a result of this forced resettlement by the Bangladeshi government. In order to protect their ancestral lands and distinct cultural identity, the indigenous political leaders stimulated the common people from diverse ethnicities to participate in resistance movements against the discriminatory political stance of the Bangladeshi government. The indigenous political leaders utilized some common grounds of identity formation such as habitat, place, method of cultivation, and lifestyles of indigenous people to separate all the non-Bengali ethnic groups from the Bengalis in the plains and hence the political authority of Bangladesh. Consequently, the terms 'Adivashi', 'Jumma' and 'Pahari' appeared in the discourse of the identity construction of the indigenous people in the CHT in recent decades. The notion of Jumma was developed in relation to jum agriculture or shifting cultivation and land rights in the CHT. The indigenous political party-the PCJSS-symbolized this notion of Jumma in order to revitalize the movement of regional autonomy, distinct cultural identity, and land rights. As described by Ahamed (2006, 375):

The symbolic use of traditional agricultural practices (jum) as collective ethnic marker is a process of displaying a shared history of common past and present, in which all ethnic groups are intimately related and attached to CHT land. The use of Jumma is, in fact, an effort to uphold a common cultural identity. In the construction of Jumma identity, the historical past is shaped by present political realities in the CHT. Therefore, in practical terms, Pahari and Jumma supplement each other in the form of collective mobilization in the CHT. 
Although the notion of Jumma was influential in the form of collective ethnic mobilization in the mid-1970s under the regional political leadership of the PCJSS, it is mainly limited to the political discourse in the postPeace Accord situation in the CHT. The common indigenous people often use the term Pahari in everyday conversations in relation to place rather than Jumma in relation to the method of agriculture. Even the indigenous political leaders use the word Pahari in their political speeches, seminars, press conferences, and in other public discourse. This is because most of these people have left their traditional shifting cultivation and are now adopting new forms of farming in the hills. For example, instead of shifting cultivation, they are practising mixed crop or mixed fruit gardening in the hills. They are relying on plough-cultivation in the well-suited low and levelled land. Thus, in changing situations and contexts, these groups of people tend to choose the term Pahari to construct their shared identity in relation to a place, sources of livelihood, and lifestyle. Place has now become the key criterion for the indigenous people in determining difference from the Bengalis; it has become a powerful symbol to create a sociopolitical platform, as this study observes.

\section{What does the Pahari Stand For?}

As described above, the people who live in the hills are the Pahari. But the question which arises is, are all the people who live in the CHT in Bangladesh Pahari? While conducting my dissertation fieldwork in Rangamati, I have experienced that most of the indigenous people use the common term Pahari to introduce themselves to visitors and tourists. It is also used while interacting with each other in various public domains. They are also identified as the Pahari by the Bengali population. This is not their actual ethnic identity; they are ethnically Chakma,
Marma, Tanchangya, Tripura, Lushai, Gurkha, or Ahamiya. People from each of these ethnic groups also use and identify with their individual ethnic identity, such as Chakma, Marma, and Tanchangya. One Pahari informant said, "Pahari is our common identity but Chakma, Tanchagya or Gurkha is our individual ethnic identity." It seems that the term Pahari is constructed based on territorial, ecological, regional, and geographical significance and its relations to the various aspects of life of people in the CHT.

Obviously, this Pahari identity has broader social, cultural and political implications, especially when it is used to mark differences from the Bengalis and to connect it to their struggle for social, economic, and political freedom (Ahamed 2006; Sen 1999). In the following section, I will examine how the place is brought into a focal point to the construction of the collective Pahari identity.

\section{How Is the Pahari Identity Linked to A Place, the CHT?}

Geographically, the CHT is a part of Hill Tripura and Arakan Yoma, branching off from the Himalayan range and continuing to the south through Assam and Hill Tripura of India to Arakan of Myanmar. The Karnaphuli is the largest of the rivers in the region. Due to the construction of a hydroelectric project known as Kaptai Dam on the Karnaphuli in 1962, a major portion of the river has turned into Kaptai Lake (Chakma 2010; Chowdhury and Rafi 2001; Schendel 1992). The hilly topography of the CHT makes a difference in economic, social, and cultural systems and lifestyles between Pahari and the people of the plains in Bangladesh. Although it is not known who first used the term Pahari, it is assumed that the indigenous people in the hills coined it from the Bengali word pahar 'hill' and emphasizing the suffix $-i$; together it means 'inhabitants of the hill', in reference to their dwelling or living place, 
reliance on hill, land, forest, and ecological system for their livelihood and subsistence economy (Ahamed 2006; Ali and Shafie 2005; Bhattacharya et al. 2005). The hill is central to the construction of cultural and sociopolitical identity of the indigenous people in the CHT. It is central because the hill is an integral part of their social, cultural and economic lives. The relationship between the hill, ecological system, environemnt and the people who live here is inseparable. The hills, forests, rivers, well-suited low and leveled land between the hills, lake, and hundreds of canals are major sources of farming, fishing, and other direct and indirect sources of livelihoods for the people who live here. The indigenous hill people traditionally depend on subsistence agriculture and they are predominantly involved in shifting cultivation, which is locally called jbum chash; they also practice plough cultivation at the fringe lands or in the well-suited low and leveled land which is situated between uplands or mountains (Ali and Shafie 2005, 81). This pattern of subsistence economy of the indigenous people in the CHT significantly differs from the semicapitalistic agricultural economy of the plains in Bangaldesh.

Thus, cultural and economic influecne of the hill, forest, and biodiversity or ecological system on the life of the Pahari is immense. The attachment of the Pahari people to this natural environment and land is inseparable. The place is reflected on every aspect of the Paharis' economic system, living pattern, housing type, food practices, rituals, belief systems, and gendered division of labor, which is markedly different from the way of life of the Bengalis of the plains. Accordingly, the local indigenous people emphasize four key criteria: place, time, nature and sources of livelihoods, and the tradition and the distinct pattern of lifestyles as the rationale for connecting place to their collective Pahari identity. In other words, social, cultural, and political construction of the Pahari identity is directly linked to the possession or protec- tion of a territory, a Pabari homeland, the CHT (Schendel 1992). In fact, the construciton of the Pahari identity is a recent sociopolitical phenonmenon in the CHT (Ahamed 2006). The Pahari, a common identity for all diverse non-Bengali ethnic groups, is emerging in response to the cultural, economic, and political discrimination created by the government and Bengalis in the recent past (e.g., the Kaptai hydroelectric project in the 1960s and the resettlement policy in the late 1970s) as well as the current social and economic relations with the Bengalis. Establishing land and territorial rights is the central issue for why the Pahari people have been struggling for decades to form a distinct cultural and sociopolitical platform and a collective identity.

A question that arises is, why are the Pahari people so concerned for their territorial rights? My recent ethnographic fieldwork in the CHT provides possible explanations. One of the explanations is that the indigenous people are concerned about their economy, future generations and their possible adaptation and coping strategies in response to increasing population and loss of land and natural resources in the hills. The impact of a changing socioeconomic situaiton, domination of the Bengali business syndicate, and the penetration of the market economy has created a challenge for the traditional subsistence economy of the indigenous farmers. As discussed above, traditionally the Pahari people used to live solely on the hills, forest, land and river for their livelihood. They would enjoy a communal and collective landownership by giving revenues to the traditional sociopolitical authority. The Pahari people who live in the hills were the owners of the hills, land, forest, and natural resources, but when the idea of propriety claims and the conception of private ownership of land was developed and implemented in the CHT, the Pahari people began to encounter a serious economic problem. As Schendel (1992, 122-123) wrote:

The territorial thinking has developed 
strongly in reaction to proprietary claims by the British crown and its successor governments, the introduction of private property rights in land, and exploitation of the region's resources. Among the inhabitants of the hills, whose precolonial forebears didn't feel any particular closeness to each other because they happened to occupy the same tract of the hill land, the possession of a homeland has now become a core element in the construction of a shared identity.

Thus, the fear of the dispossession of rights to land, hills, and natural resources is one of the main reasons for why such shared identity has been constructed despite ethnocultural differences within these groups. If the Pahari don't have rights to the hills, it might create a great threat to their existence, to their livelihood and economy, culture and identity. Since the hill people are generationally dependent on the traditional knowledge of shifting cultivation and other modern forms of farming in the hills, it seems to be difficult for many of them to find alternative means of livelihood.

\section{"Collectivity" and "OTherness": \\ Comparing the Pahari-Bengali IDENTITY CONSTRUCTION}

Discussion clearly reflects that the social, cultural, and political construction of the Pahari is deeply connected to a specific place, the CHT. This Pahari identity has its local meaning and contexts, interpretations, and enormous implications for the lives of the people concerned. As Ahamed (2006, 372) observed:

The usage of the term Pahari bears its own inclusive mechanism of cultural and geographical boundary maintenance specific to CHT. Pahar symbolises the special distinction of territorial and cultural boundary between Pahari and Bengali people, highlights the only authenthic home and place for the Pahari. Their unique lifestyle in $\mathrm{CHT}$ has become part of their pride and sense of belonging, which as understood by them, necessarily refutes cultural diversity among them.

Nevertheless, this study identifies three key aspects-place, social life, and economic-political relations-between Bengali and nonBengali ethnicities in the CHT. These factors are intertwined and inseparable to the collective Pahari identity construction process. It has already been discussed above how place and political-historical relationships with the Bangladeshi state and the Bengalis together influence the indigenous people in forming various shared identities (e.g., the Jumma, the Pahari). Now I will discuss how culturally differentiated ethnic groups of people converge to form a shared identity and how they separate other groups in context of social and cultural aspects of life and inter-ethnic relations.

\section{Ethnic boundaries and convergence of diverse ethnicities}

The place is not just a setting for social and economic actions or the reflections of a particular way of life of the people. The place can be used to represent the temporary grounding of ideas as well, as we experienced in the case of the CHT (Rodman 1992). Besides, the territorial and ethnic boundaries of the social relations among the Pahari play a critical role in creating an alliance within or alienating others (i.e., the Bengalis). As described above, different ethnic groups such as the Chakma, Marma, Tripura, Tanchangya, Lushai, Ahamiya, and Gurkha live in this study community. There is a certain ethnic boundary for each of these ethnic groups based on their distinctive cultural and social organizations (e.g., religion, language, marriage, kinship, sociopolitical leadership system). Despite their ethnic and cultural differences, all of these ethnic groups adopt a common sociopolitical identity, the Pahari. This dimension of the convergence of diverse ethnicities can be explained in relation to the conception of "ethnic boundary":

The ethnic boundary canalize social 
life-it entails a frequently quite complex oragnization of behaviour and social relations. The identification of another person as a fellow member of an ethnic group implies a sharing of criteria for evaluation and judgement. It thus entails the assumption that the two are fundamentally 'playing the same game', and this means that there is between them a potential for diversification and expansion of their social relaitonships to cover eventually all different sectors and domains of activity [Barth 1970, 15].

In this perspective, the construction of the Pahari identity within diverse ethnic groups in the CHT is based on the sharing criteria for evaluation and judgement (Barth 1970, 15). Of course, there are certain individual and group interests and other social and economic forces that act in motivating these diverse ethnic groups to form a shared identity. For instance, they live in the same place, and they have a common interest to protect their land and natural resources from the intrusion of the state and the Bengalis. They are also exploited and discriminated socially and economically by the Bengalis in their everyday life. In order to achieve relief from the domination and exploitation they face, the Pahari want to establish social, economic, and political freedoms. There is also a closeness of social life among these ethnic groups as they share some common rituals and cultural practices including Biju, Boishabi, etc. The Biju, the biggest social festival of the indigenous people of the CHT (for more information, see The Daily Star 2010), is celebrated for three consective days beginning from the second-last day of the past Bengali year to the first day of the new Bengali year-that is, from April 12 to April 14. The grand festival is to say goodbye to the past year's sorrows and welcome the new year with hope for a prosperous future. The first day is marked by floating flowers on Kaptai Lake, rivers, or water fountains seeking divine blessings and prosperity. The following day is passed by preparing and serving special items of foods such as cakes, sweetmeat, and pachan (mixed vegetables) to relatives and guests. Finally, the first day of the Bengali New Year is marked by inviting guests and visiting relatives and tasting food including liquor, and blissing the children and youth by the elders (Chakma 2006, 20-22). Thus, these common social life practices preformed by the people in the CHT aid in constructing the common sociopolitical identity: the Pahari.

\section{Separating and constructing 'Other'}

The Pahari people use the demarcation of territorial and cultural boundaries as the main criteria in demonstrating their cultural distinctiveness from the Bengalis. Patterns of inter-ethnic relations are also a key aspect that mark differences between the Pahari and the Bengalis. In most cases, as this study observes, the Pahari people identify the Bengalis as the "settlers" and by other negative terms such as Bangiya (strangers/outsiders from the plains). From an ethno-cultural point of view, all of the indigenous people are nonMuslims and their mother tongue isn't Bengali. In this regard, the identification of the Bengalis as outsiders or Bangiya implies that, as Barth $(1970,15)$ describes, there is
a recognition of limitations on shared understandings, differences in criteria for judgement of value and performance, and a restriction of interaction to sectors of assumed common understanding and mutual interest.

In other words, there is a negative relationship of "assumed common understanding and mutual interest" (Barth 1970, 15) regarding social, economic, and political issues between the Pahari and the Bengalis in the CHT. The relationship between the Pahari and the Bengali is conflictive because the immigrant Bengalis were settled in the lands of the CHT previously occupied by the Pahari. There is also an issue of lack of mutual trust and shared understanding, as these two rival groups are struggling with each other to se- 
cure their supremacy in the $\mathrm{CHT}$ region in regard to land, economic and political rights.

The Bengali settlers began migrating after the independence of Bangladesh in 1971. Based on the narratives of key informants from Pahari communities, this study found that the social, economic, and political relationship between the Pahari and the Bengalis was positive before the liberation war in 1971, but the situation has changed. Bengalis are now perceived as "bad people," "rapist," "torturer," and "killer" by the Pahari (Schendel 1992, 122). Since the Bengalis were allegedly involved in various misdeeds and criminal activities such as transgressing the lands and natural resources owned by the Pahari, kidnapping, rape, killing, and extortion, the Pahari began to change their previous positive perceptions (Halim et al. 2005; Karim 1998). Many indigenous people lost their land and homes and became refugees as a result of the social instability created by rehabilitation of the Bengali people in the $\mathrm{CHT}$ region. This resettlement policy was (and still is) considered a nuisance, unacceptable, and a discriminatory political decision which has been directly responsible for deteriorating inter-ethnic relationships between the Pahari and the Bengalis. Even the relationship between the Pahari and the Bengalis who have been living in the CHT since the British period (1760-1947) disintegrated. The Pahari people hardly made a distinction between Pahari and Bengali in the past. The Pahari were used to living together peacefully, they co-operated with each other, and they rarely participated in ethnic conflict and violence like murder and arson after the resettlement policy was established in the mid-1970s. Consequently, by identifying the Bengalis as Bangiya, the Pahari people are separating the Bengalis from the rights to live in the hills. A key Bengali informant said, "There are still some Pahari people who cannot accept the presence of Bengali settlers.
That day a Pahari was saying that it is our region we cannot accept the presence of Bengali settlers here."2 This statement implies that the Pahari are the authentic owners of the hills and lands in the CHT, and the Pahari still view the presence of the Bengali settlers as problematic, a barrier for their social and economic development.

\section{Change, Asymmetry of Power, AND CONTESTED IDENTITY}

As manifested in the above discussion, the construction of the Pahari identity is not independent of prejudgements and contestation. It is more of the regional, territorial, economic, and sociopolitical than mere cultural similarities and differences between the Pahari and the Bengalis. Besides the recent Bengali immigrants, local Pahari often address them as settlers, Bangiya or sometimes outsiders, there are a large number of Bengali people who have been living in the CHT region since the British colonial period. Note, however, the British local administration settled some Bengali farmers from the nearby Chittagong district to teach the Pahari how to use the plough and other modern technologies and to increase agricultural production beyond that of the subsistence economy of jum cultivation. The Pahari people exclude the Bengalis from the Pahari categorization based on their cultural differences such as language, religion, economic activities, kinship, and political systems (Ahamed 2006, 371; Schendel 1992, 106).

The logic of cultural difference used in separating the Pahari from the Bengalis has weakened as the Pahari people are experiencing a significant cultural and sociopolitical change in the post-peace accord development era in the CHT. This study identified that the cultural differences between the Pahari and Bengali has been reduced in the domains of the style of dress, language, marriage, and sociopolitical leadership. Most Pahari men and

${ }^{2}$ Momen Ahamed, interview by Ashraf Ali. Rangamati, July 27, 2009, Interview \#6. 
women wear Bengali dress, speak in Bengali dialect, and have adopted cultural traits and rituals from the pattern of Bengali marriage. Religious transformation and interethnic marriage are notable examples of cultural change in the CHT. Pahari groups such as the Tripura and Ahamiya are converting to the religion of Christianity, abandoning their traditional religion of Hinduism. Change of religion together with ethnic identity is also a recent phenomenon in the CHT. For instance, women have to change their religious and ethnic identities and even their personal names if they are going to marry someone from other than their own ethnic group and religion. Pahari and non-Muslim Bengali women have to sacrifice their traditional religion of Buddhism or Hinduism whenever they wish to have husbands from other ethnicities such as Bengali Muslim. A total of 37 cases of interethnic marriages were identified in recent years in the study area: within the Pahari community, 25; between Pahari men and Bengali Hindu women, 6; and between Pahari women and Bengali men, 6. In the third category, all the Pahari women, including Marma, Tanchangya, Ahamiya, and Gurkha, had to change their traditional religion, ethnic identity, titles, and names. They had to adopt a new ethnic and religious identity in accordance with the religious and patriarchal tradition of their Bengali Muslim husbands. Interestingly, there is no instance where a Bengali Muslim woman married a non-Muslim man. Based on the narratives of the couples this study observed, interethnic marriages may happen because of passion, social and cultural proximity, and economic factors. Social, cultural, and religious resemblance is found as one of the dominant factors for the high incidence of inter-ethnic marriage between non-Muslim Bengali and non-Bengali people in the study area. The weak socioeconomic background of parents sometimes may have forced some young women to choose life partners from other ethnicities and religions.
Dress, behavior, attitude, and pattern of interaction with Bengali people have changed significantly for these ethnicities over the last few years. One of the key indicators of changing inter-ethnic relationships is different social and cultural functions and food practices. Nowadays, most marriage and circumcision ceremonies, death or birth rituals, and other major sociocultural and religious festivals (e.g., Biju, Eid, Pujas) are visibly marked with the attendance of multiethnic groups of people with different types of foods. Bengali people participate in the social occasions of indigenous people (e.g., Biju, marriage ceremony) and indigenous people participate in the socioreligious events of $\mathrm{Pu}$ jas and marriage ceremonies of the Hindus, and Eid of the Muslims. If a Muslim person organizes a ceremonial occasion, he invites guests from multiethnic religious groups including Hindus, Christians, and Buddhists, and including Chakma, Marma, Tanchangya people. In this case, the host will serve food that can be eaten by all the guests. For example, chicken or mutton will be served instead of beef. Similarly, a Hindu or Chakma person will serve food that is not taboo for any guest attending there. In other words, food taboos are seriously taken into consideration for inviting guests from different ethnicities. Such a trend of social and cultural behavior stands as a symbol of respect and tolerance for each other's social and cultural practices. The personal experience of eating together in a given place under certain circumstances may transform the event as a whole into a shared and collective experience of mutual trust and respect, equity, and pleasure. Thus, sharing foods and eating together can be a powerful symbol of social solidarity, friendship, and celebration (Korsmeyer 1999). Such changes in the lives of the Pahari and the Bengalis indicates that the antagonistic relationship between these two groups is diminishing, at least to some extent.

Change has also been observed in the pattern of dress used and worn by indige- 
nous girls and women, particularly the Chakma, Marma, Tripura, and Tanchnagya, who are traditionally used to wearing a slightly shorter dress than that of Bengali girls and women. They are now tending to leave their traditional dress for certain social and economic realities. In order to better adapt to changing social and cultural situations, and to participate in educational institutions or in other public domains, Pahari girls and women are adopting the style of dress from the cultural mainstream in Bangladesh. Educated girls seem to have a tendency to wear Bengali-style shalwar kamiz, a three-piece dress; indigenous women mostly wear the saree like the Bengali women, leaving their traditional thamis and pinon when they are out of the home. Of course, they still wear their traditional dresses in their own traditional social and cultural programs. Change has also been observed in the dress of the indigenous men. This change is largely influenced by the greater exposure of the Pahari people to the wider society in Bangladesh, the increasing rate of education, and the positive interaction with the Bengalis.

The Pahari people have also experienced an important change in terms of their traditional sociopolitical structure in the CHT. Unlike the other parts of Bangladesh, the CHT has local government administration with the traditional three administrative circles - the Chakma Circle, the Mong Circle, and the Bomong Circle-for three separate hill districts-Rangamati, Khagrachari, and Bandarban, respectively. Each circle is divided into a number of Mouras, and each Monza, a group of villages regarded as an administrative unit of government, particularly for revenue collection, is further divided into hamlets or villages (Zabarang Kalyan Samity 2012). The Circle Chief is mainly responsible for administrative functions including land and revenue and dispute resolution. Each Mouza has its own headman to collect revenue for the Circle Chief, and a Karbari assists the headman in resolving internal social conflicts (e.g., marriage, divorce) or disputes over land under their jurisdiction. This political leadership is traditionally dominated by males. However, the effectiveness of this sociopolitical system has been reduced with the introduction of local government administration (e.g., Union Parishad, Municipality) in the CHT. For instance, the study locality is part of Bangladesh's Rangamati Municipality. This is also under the jurisdiction of the Chakma Circle Chief, a headman, and a Karbari. The local government representatives are elected both from the Bengali and the Pahari communities. The changing role of the traditional sociopolitical leadership brings a different experience for the Pahari people as they are exposed to more dynamic and democratic political systems instead of patriarchal, male dominated, hierarchical power structures. In practice, most disputes centering on land, marriage, and other social issues are now settled by the elected political representatives, police stations, or by the courts.

In this connection, the construction of collective Pahari identity based on cultural demarcation between the non-Bengali ethnicities in the CHT and the Bengalis of the plains involves overlapping and contestation. Moreover, there exists social and economic inequality and asymmetry of power relations within the diverse ethnic groups such as the Chakmas, which are percieved as the most advanced among all the ethnic minorities in terms of their social, economic, and political development in the CHT.

Internal power asymmetries, domination, and deprivation are some of the common predicaments which appear for the indigenous people, turning a shared identity (e.g., Jumma, Pahari) into a "political pipe-dream" (Schendel 1992, 124). Even if it is compared with that of the Bengalis, the Chakmas are almost in line with the Bengalis because they hold some important economic and political positions in Rangamati, including on the CHT Regional Council and Ran- 
gamati Hill District Council, as well as the Chakma Circle Chief; they are also involved in different government and non-governmental organizations with the Bengalis. As Schendel $(1992,124)$ wrote:

\begin{abstract}
Acceptance of the Jumma identity depends on the degree to which old intergroup perceptions can be neutralized. For example, some groups consider themselves more 'advanced' than others; this is especially clear in the traditional division between 'river-valley' groups (e.g., Marma and Chakma) and 'hill-top' groups (e.g., Bawm, Mru and Khumi).
\end{abstract}

From this persepctive, the idea of a collective identity - the Pahari-is equivocal, especially because of internal dynamics of domination, hierarchies, ignorance, and exploitation. It seems that there exits a recognition of limitations on shared understandings and mutual interest within the diverse ethnicities (Barth 1970, 15). For example, the Chakmas are in better positions, both in the education and government sectors, because they can avail the special quota allotted for all the disadvantaged ethnic groups in the CHT. Small ethnic groups such as the Tanchangya, Pankhua, Khiang, Mro, Khumi, and Bawam are deprived of these social and economic opportunities because they are relatively marginal, both in terms of economic and political power (Ali and Ahsan 2005; Uddin 2008). The way of life of the most of these ethnic groups has meanwhile been influenced by the changing socialpolitical, cultural, and economic situations in recent years. Many of the Pahari have gradually been connected with the wider Bangladeshi society because of their increasing physical mobility. Increasing population growth, land loss, and limited or lack of sources of livelihoods in the CHT have forced both poor and non-poor Pahari to migrate to other towns and cities in Bangladesh. Pahari people often migrate to urban centers such as Chittagong and Dhaka to seek jobs, business and education opportunities, and for other purposes. This is inevitable for a majority of the Pahari in the CHT, given current socioeconomic realities. In practical terms, both the internal and external dynamics of the social, political, economic lives of the CHT people appear as fundamental challenges to strengthening feelings of belonging to a community, to mobilizing the diverse ethnicities in order to bring all members together in one political platform - the Pahari.

\section{Conclusions}

The place-the CHT-is central to the construction of the collecitve Pahari identity. The Pahari, like Jumma, has appeared as a form of imagined community, promoting a sense of community-belonging among diverse ethnicities in the CHT despite the existence of inequality, asymmetry of power, and contradiction within (Anderson 2006). The collective Pahari identity has been represented as a sysmbol of protest against the discriminatory political policy of the state of Bangladesh and the intrusion of the Bengalis in the CHT. For the Pahari people, the CHT has a "unique reality" (Rodman 1992). It seems that there is a shared meaning when the Pahari separate them from the Bengalis of the plains. Certainly, there is a significant difference of cultural and historical experiences between the peoples who live in the hills and in the plains. Culturally, the Pahari set themselves apart from the Bengalis in terms of their non-Islamic religious outlook and different mother tongues. Historically, the Pahari people have shared a unique experience, as they have been repeatedly invaded by outsiders since before the colonial past (Schendel 1992). Of course, there is in actuality much ethnic mobilization based on cultural and historical background. For example, the indigenous political leadership has succeeded in mobilizing the diverse ethnic groups through the construction of such shared identities as the Jumma in the mid1970s. The indigenous political movement under the leadership of the PCJSS from the 1970s to the 1990s contested the military force of Bangladesh, a protest against dis- 
criminatory political policies, including the influx of the Bengalis from the plains into the CHT, led to the CHT Peace Accord in 1997. The government declared to protect social, economic, and political rights of indigenous people, though the major provision of this agreement has not been fully implemented yet. Nevertheless, the Pahari political leadership is encountering internal political rivalry from a new regional political party, the United People's Democratic Front (UPDF), formed in 1998 by a group of the Pahari protesting the peace accord between the PCJSS and the Government of Bangladesh (Uddin 2010, 27). The UPDF demands regional autonomy for the CHT, which is not a provision in the peace accord. Both the PCJSS and the UPDF are currently involved in political dispute over this issue. Whereas the PCJSS seems liberal, the UPDF is very much conservative in maintaining political relations with Bengalis and the Bangladeshi state, especially in pursuing their political demands. Nevertheless, the political goal of both parties is the same: to relieve the Pahari from the economic and political domination of the Bengalis and the nation-state of Bangladesh.

I have argued here that the construction of the Pahari identity is part of the continuous political resistance against the recurrent discrimination, deprivation, and marginalization by the state of Bangladesh, manifested in part by a demarcation of identity between Pahari and Bengalis. The Pahari identity becomes more meaningful and significant when it is used as a voice against the discriminatory economic and political stance of the Government of Bangladesh; it is a powerful social, economic, and political symbol when people dedicate themselves to protecting their rights to land and livelihood. Instead of internal cultural differences, the Indigenous Pahari people bring place to the forefront in the construction of this identity shared by diverse ethnicities. They deliberately exclude Bengalis from the Pahari identity despite some signs of increasingly positive social and cultural relations. In this regard, the dynamic construct of place-the CHT-represents the innovative conceptualization of the indigenous people (e.g., the Jumma, the Pahari). This is part of an endeavor to achieve social, economic, and political freedoms (Sen 1999). The idea of 'Pahari' has already been turned into a form of political identity and into a salient social and economic movement. Dispossession of land, changes in traditional patterns of livelihood, deprivations, and uncertainty about the economic future are key factors influencing the Pahari to form a shared sociopolitical identity in the CHT. Unlike the direct confrontation with the Bangladesh state that took place in the mid1970s, the Pahari people are now engaged in devising new strategies to adapt better to changing times. Obviously, the construction of a shared sociopolitical Pahari identity is part of this maneuver. Thus, the invention of the Pahari identity itself is a response to contemporary societal changes, demonstrating the common goal of turning this collective identity into a form of political existence separate from the influence of the nationstate of Bangladesh.

\section{ACKNOWLEDGEMENTS}

I am grateful to the Department of Anthropology, University of Alberta, for granting me both research and travel grants for conducting my PhD dissertation fieldwork in Bangladesh in 2009 and 2011. I am immensely indebted to my PhD supervisor, Dr. Helen Vallianatos, for her invaluable inspiration, continuous academic support, comments, suggestions, and direction throughout the process of conducting and completing my fieldwork and research. I must express my immense gratitude and respect to all of my research participants, key informants, NGO officials and workers. Without their keen interest, valuable time, and profound and generous support, the successful completion of my fieldwork in the CHT, Bangladesh, would have been quite impossible. I am profoundly grateful to them for providing their full sup- 
port throughout my fieldwork in Bangladesh.

\section{REFERENCES}

Ahamed, Farid. 2006. "Culture Becomes Politics, Politics Becomes Culture: Pahari Identity and Ethnic Mobilization in CHT, Bangladesh." In Anthropology on the Move: Contextualizing Culture Studies in Bangladesh, edited by Zahidul Islam and Hasan Shafie, pp. 367-382. Dhaka: University of Dhaka. Ahsan, Syed, and Bhumitra Chakma. 1989. "Problems of National Integration in Bangladesh: The Chittagong Hill Tracts." Asian Survey 29(10):959-970.

Ali, Ahsan, and Hasan Shafie. 2005. Entitlement and Deprivation: Selected Cases of Discrimination in Bangladesh. Dhaka: UNESCO.

Anderson, Benedict. 2006. Imagined Communities: Reflections on the Origin and Spread of Nationalism. London: Verso.

Arens, Jenne, and Kirti N. Chakma. 2002. "Bangladesh: Indigenous Struggle in the Chittagong Hill Tracts." In Searching for Peace in Central and South Asia: An Overview of Conflict Prevention and Peacebuilding Activities, edited by Monique Mekenkamp, Paul van Tongeren, and Hans van de Veen, pp. 304-324. Boulder: Lynne Rienner Publishers.

BARTH, FredRIK. 1970. Introduction to Ethnic Groups and Boundaries: The Social Organization of Culture Difference. London: George Allen \& Unwin.

Bhattacharya, Samit, Monojit Chowdhury, and Sudeshna Sarkar. 2005. "Inflectional Morphology Synthesis for Bengali Noun, Pronoun and Verb System." Proceedings of the National Conference on Computer Processing of Bangladesh 2005:34-43.

Bernard, Harvey R. 2010. Analyzing Qualitative Data: Systematic Approaches. London: Sage.

Bhikkhu, Prajnalankar. 2007. "CHT on Historical Outline with Special Reference to Its Current Situation." Global Politician. Accessed April 1, 2012. http://www. globalpolitician.com/23185-india.

Chakma, Bhumitra. 2010. "The post-colo- nial state and minorities: ethnocide in the Chittagong Hill Tracts, Bangladesh." Commonwealth and Comparative Politics 48(3):281300.

Chakma, Shardindu S. 2006. The Festivals of the Chittagong Hill Tracts, Celebration and Other Issues (in Bengali). Dhaka: AnkurPrakashani.

Chowdhury, Rahman and Muhammad, Rafi. 2001. Counting the Hills: Assessing Development in Chittagong Hill Tracts. Dhaka: The University Press Limited.

Daily Star, The (Staff Correspondent). 2010. "Hill districts wear a festive look on first day of Biju." April 13, 2010, online edition. http://www.thedailystar.net/newDesign/news-details.php?nid=134155.

. 2011. "Indigenous issue draws arguments." August 8, 2011, online edition. http://www.thedailystar.net/newDesign/ news-details.php?nid=197739.

FetTerman, David. 2010 Ethnography: Step-bystep. Los Angeles: SAGE.

Halim, Sadeka, Susmita Chakma, and Rajib Chakma. 2005. Gender and Human Rights Violation in Chittagong Hill Tracts: The Post Accord Situation. Dhaka: Bangladesh Freedom Foundation.

Hammersley, Martyn, and Paul Atkinson. 2007. Ethnography: Principles in Practice. London: Routledge.

Karim, Lamia. 1998. "Pushed to the Margins: Adivasi peoples in Bangladesh and the case of Kalpana Chakma." Contemporary South Asia 7(3):301-316.

Korsmeyer, Carolyn. 1999. Making Sense of Taste: Food and Philosophy. New York: Cornell University Press.

Levene, Mark. 1999. "The Chittagong Hill Tracts: A case study in the political economy of 'creeping' genocide." Third World Quarterly 20(2):339-369.

Mohsin, Amena. 2004. "Gendered Nation, Gendered Peace." Indian Journal of Gender Studies 11(1):43-64.

Nasreen, Zobaida, and Masahiko Togawa. 2002. "Politics of Development: 'Pahari- 
Bengali' Discourse in the Chittagong Hill Tracts." Journal of International Development and Cooperation 9(1):97-112.

UdDin, Nasir. 2008. "Living on the Margin: The Positioning of the 'Khumi within the Sociopolitical and Ethnic History of the Chittagong Hill Tracts." Asian Ethnicity 9(1):33-53.

Rodman, Margaret. 1992. "Empowering Place: Multilocality and Multivocality." American Anthropologist 94(3):640-656.

Sen, Amartya. 1999. Development as Freedom. New York: Knopf.

United Nations Development Programme. 2009. Socio-economic Baseline Survey of Chittagong Hill Tracts. Dhaka: UNDP

Uddin, Muhammad. 2010. "Change in Language, Communication and Thought: A Study on Linguistic Discrimination against the Indigenous People of the Chittagong Hill Tracts, Bangladesh." Studies in Literature and Language 1(1):25-37.

VAN SCHENDEL, Willem. 1992. "The Invention of the 'Jummas': State Formation and Ethnicity in Southeastern Bangladesh." Modern Asian Studies 26(1):95-128.

Zabarang Kalyan Samity. "History of the Chittagong Hill Tracts." Accessed March 30, 2012. http://zks-bd.org/thechittagong-hill-tracts/history-of-the-chittagong-hill-tracts/. 